\title{
Prevalence of dementia in the People's Republic of China from 1985 to 2015: a systematic review and meta-regression analysis
}

Yangjun Zhu' ${ }^{1}$ Hao Liu², Xi-Li Lu², Bo Zhang ${ }^{2}$, Wanwen Weng ${ }^{2}$, Jun Yang ${ }^{2}$, Jun Zhang ${ }^{2}$ and Meng-Jie Dong 2,3* $^{*}$

\begin{abstract}
Background: In China, the most populous developing country in the world, dementia represents a serious challenge. We performed a large-scale systematic review and meta-regression analysis to elucidate the prevalence of dementia and its subtypes and to identify potential factors underlying the differences between articles.

Methods: A comprehensive literature search was conducted in the following databases to identify studies published up to December 2015: Cochrane Library, CBMDISK, Chongqing VIP, CNKI, PubMed and EMBASE. All statistical analyses (including subtype and meta-regression analyses) were performed with $\mathrm{R}$ version 3.3.3.

Results: In total, 51 surveys were selected. The pooled prevalence rates of dementia and its main subtypes, namely, Alzheimer's disease (AD) and vascular dementia (VAD), for the population aged 55 years and older were $4.03,2.44$ and $1.09 \%$, respectively. The outcomes showed that the meta-regression analysis was affected by the publication year, sample size, region and diagnostic criteria.

Conclusions: Our analysis provided reliable estimates of the prevalence of dementia/ AD/ VD over the past 30 years, which may be affected by education level, and diagnostic criteria. The prevalence of ADNAD was higher in northern than in southern China, which warrants further study.
\end{abstract}

Keywords: Dementia, Alzheimer's disease, Vascular dementia, China, Prevalence

\section{Background}

Dementia is a neurological condition that mostly occurs in individuals older than 60 years and has become a significant global problem in most developed and developing countries due to population ageing. Dementia can diminish a patient's quality of life and lead to high healthcare costs. A recent meta-analysis published by Fiest et al. [1] reported that the pooled prevalence of dementia worldwide among the elderly aged 60 years and older was $4.86 \%$ (95\% CI: $4.20-5.63 \%)$. In China, the

\footnotetext{
* Correspondence: dmjlzf2016@zju.edu.cn

${ }^{2}$ The Department of Nuclear Medicine, the First Affiliated Hospital, College of Medicine, Zhejiang University, 79 QingChun Road, Hangzhou 310003, People's Republic of China

${ }^{3}$ Key Laboratory of Precision Diagnosis and Treatment for Hepatobiliary and Pancreatic Tumours of Zhejiang Province, Hangzhou 310003, People's Republic of China

Full list of author information is available at the end of the article
}

most populous developing country in the world, dementia represents a serious challenge. Dementia in mainland China has been investigated by several groups and seems to be increasing, according to recent reviews [2-4]. Our group previously published a systemic review including 25 studies in 2007 [2], and the review demonstrated that the pooled prevalence of dementia in the elderly population aged 60 years and older was 2.8\% (95\% CI: $2.5-$ $3.1 \%)$. Wu et al. [4] revealed the pooled prevalence of dementia from the 76 studies was $3.8 \%$ (95\% CI: 3.4, 4.2) with the range from 0.6 to $17.2 \%$ for the population aged 60 and over in 2013. Wu et al. [4] was also the first to separate mainland China into three areas (north, central and south) and to discuss the prevalence of dementia in an age-standardized pattern. The authors showed an increasing prevalence from north to south and that the discrepancy between the areas could not be explained by

(C) The Author(s). 2019 Open Access This article is distributed under the terms of the Creative Commons Attribution 4.0 International License (http://creativecommons.org/licenses/by/4.0/), which permits unrestricted use, distribution, and 
the differences in methodological factors, including the age range and diagnostic criteria. However, Wu et al. [4] did not analyse the prevalence of dementia subtypes (primary Alzheimer's disease (AD) and vascular disease (VAD)) and did not discuss their findings in the context of chronology. This article provides a detailed study of dementia and its subtypes in mainland China up to December 2015 and attempts to identify potential factors underlying the differences between articles through a meta-regression analysis.

\section{Methods}

\section{Search strategy and selection criteria}

Two reviewers independently searched the Cochrane Library, CBMDISK, Chongqing VIP, CNKI, PubMed and EMBASE databases up to December 2015 using 'Alzheimer's disease' or 'AD', 'vascular dementia' or 'VAD', 'dementia', and 'prevalence' or 'associated risk' or 'infection status' or 'epidemic status' or surveillance' as the major search terms. There were no language limitations, but the study did not include epidemiological studies in the areas of Hong Kong, Macao and Taiwan because these data were not easily accessible. In addition, the authors screened the reference lists of the identified articles and corresponded with the study investigators using the approach recommended by the Preferred Reporting Items for Systematic Reviews and Meta-Analyses (PRISMA) guidelines.

The inclusion criteria were as follows: (i) case collection based on a field survey; (ii) studies published in peer-reviewed journals; (iii) the population in the investigations was 55 years and older; (in our study, data from participants below 55 years of age were omitted); and (iv) used a validated method to assess the dementia diagnosis (through both a screening phase and a diagnostic phase). The exclusion criteria were as follows: (i) studies that used the Newcastle-Ottawa scale (NOS); (ii) articles with repeated cases; (iii) articles of inferior quality or with incomplete information; and (iv) unavailable articles (i.e., reviews, comments, and abstracts).

\section{Data extraction}

In the screening stage, all samples were screened using brief cognitive tests, including the Mini-Mental State Examination (MMSE), the Blessed Dementia Scale (BDS) and the Hasegawa Dementia Scale (HDS). Positive screens were identified when the samples scored below the cut-off point on one or more tests or were clinically diagnosed with dementia. In the diagnosis stage, positive screens were further diagnosed by experienced physicians with the assistance of laboratory and neuropsychological tests.
The clinical diagnostic criteria used in the 50 studies included the DSM-III (the Diagnostic and Statistical Manual of Mental Disorders, Third Edition) [5-7], DSM-III-R (the Diagnostic and Statistical Manual of Mental Disorders, Third Edition) [8-23], DSM-IV (the Diagnostic and Statistical Manual of Mental Disorders, Fourth Edition) [24-39], DSM-IV-R (the Diagnostic and Statistical Manual of Mental Disorders, Fourth Edition, revised) [40-47], ICD-10 (international Classification of diseases-10) $[5,13,15]$ and CCMD (Chinese Classification and Diagnostic Criteria of Mental Disorders) [48]. The NINCDS-ADRDA (National Institutes of Neurological Disorders and Stroke-Alzheimer's Disease and Related Disorders Association) criteria were used to diagnose probable AD, and the NINDS-AIREN (National Institute of Neurological Disorders and Stroke and Association International pour la Recherche et 1'Enseignement en Neurosciences) criteria and the Hachinski Ischaemia Score were used to diagnose VAD. Other dementias, such as mixed dementia, dementia with Lewy bodies, Parkinson's disease with dementia, and alcoholic dementia, were defined using globally accepted criteria.

The detailed information extracted from the articles included the following: (i) basic information, including the author, type of publication and publication year; (ii) study design and tools, such as screening methods and tools, diagnostic criteria and sampling methods; (iii) characteristics of the study population, including age, location, occupation and education; and (iv) the prevalence of dementia and its subtypes.

Full manuscripts of the potentially acceptable studies were screened by two reviewers. The same two authors independently assessed the risk of bias of these nonrandomized studies using a modified version of the Newcastle-Ottawa Scale (NOS), which assesses the quality of nonrandomized studies based on design, content and ease of use to facilitate the task of incorporating quality assessments into the interpretation of meta-analytic results. Disagreements were resolved via consensus after discussion with a third author.

\section{Statistical analysis and heterogeneity}

The prevalence was calculated with the variance-stabilizing double arcsine transformation and weighted towards $50 \%$ to include studies with a low dementia prevalence [49]. The 95\% confidence intervals (CIs) were calculated using the Wilson method [50]. Two-sided $p$ values $<0.05$ were considered significant. A $p$ value of Cochrane's $\mathrm{Q}$ test $<0.1$ or an $\mathrm{I}^{2}>50 \%$ was defined as indicating significant heterogeneity between studies. Due to the high heterogeneity observed $\left(\mathrm{I}^{2}>75 \%\right)$, random effects models were used for the pooled statistical analyses. To identify factors that influenced the prevalence 
of dementia and its subtypes (AD and VAD), the characteristics of the cases, including gender, age, occupation, educations, and residence, were divided into diverse groups for analysis. We also performed subgroup analyses based on the specific region or publication year of the study. Publication bias was estimated using Egger's test.

Due to the high heterogeneity, we further investigated the potential sources of heterogeneity via a meta-regression analysis. All studies were allocated into diverse groups according to their potentially relevant characteristics. The suspected factors were analysed using a univariate model including the (i) publication year (before and including the year 2000 versus after 2000), (ii) geographical region (north China versus central and south China), (iii) living area (urban only versus rural only and mixed), (iv) sample size (> 3000 versus $\leq 3000$ ), and (v) diagnostic method (DSM-/IV/IV-R versus others). Furthermore, we subdivided the geographical regions/diagnostic methods into $7 / 4$ groups, respectively, and analysed these factors using a multivariate analysis model.
All the analyses were performed with $\mathrm{R}$ version 3.3.3 (Microsoft Corporation, Redmond, WA, USA). The PRISMA guidelines were followed throughout the entire process.

\section{Data availability}

All data generated or analysed during this study are included in this published article (and its Supplementary Information files).

\section{Results}

\section{Study inclusion}

We strictly screened 1230 studies in a step-by-step manner based on the inclusion criteria. Ultimately, 51 surveys from 50 articles were included after the search process, including 49 studies that reported one survey and 1 study that reported two surveys due to differences in nationality (Han/Kazak nationalities) (Fig. 1).

\section{Descriptive statistics}

A total of 166,068 people aged 55 years or older (including 78,603 males and 87,465 females) were gathered

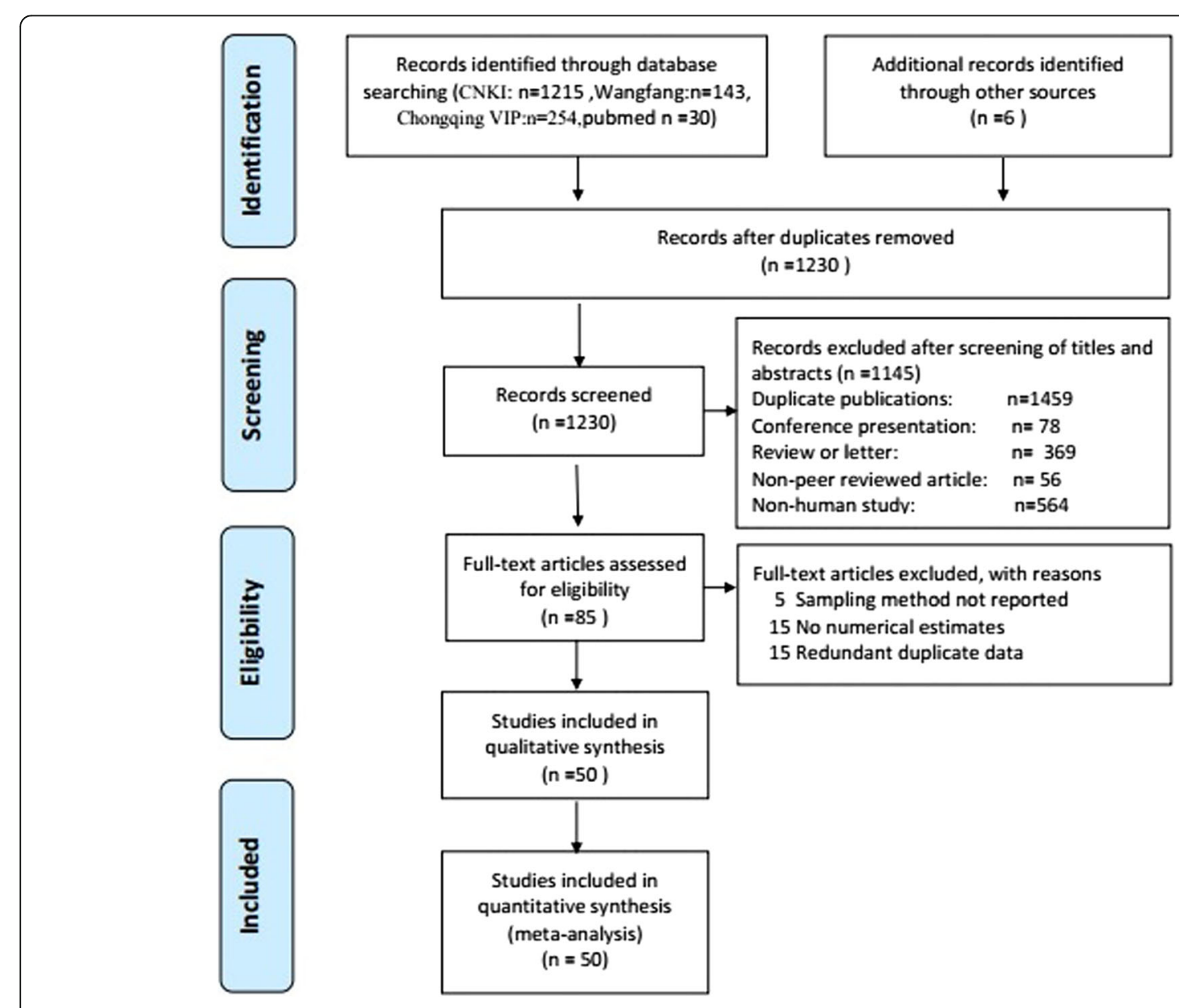

Fig. 1 The detailed search process 
from all 51 surveys; the publication year ranged from 1985 to 2015. The locations of all 51 surveys were distributed into 3 areas, including 7 regions (north area: north/northeast/northwest China; central area: central/ east China; and south area: south/southwest China) and then subdivided into 23 provinces and municipalities. Detailed information regarding the study characteristics is shown in Table 1.

The quality scores of the studies were 7-9 (average $=8.412$ ) when evaluated using the Newcastle-Ottawa quality assessment criteria; the score components for all 50 individual studies are shown in Additional file 1.

\section{Analysis of outcomes \\ Prevalence of dementia}

All 51 surveys provided the number of patients with dementia, which was divided by the different pathological subtypes (AD, VAD and others). Estimates of the dementia prevalence ranged from $0.75-11.86 \%$, and the pooled prevalence of dementia was 4.03\% (95\% CI: $3.46-4.70 \%)$. The pooled prevalence of $\mathrm{AD} / \mathrm{VAD}$ was $2.44 \% \quad(95 \%$ CI: $\quad 2.06-2.89 \%) / 1.09 \% \quad(95 \%$ CI: $\quad 0.91-$ $1.31 \%$ ), with ranges from $0.19-9.29 \% / 0.18-3.64 \%$, respectively (see Additional file 2). For other dementia subtypes, such as Parkinson's disease, the prevalence $(0.09 \%[0.07 \% ; 0.12 \%])$ was much smaller than that for $\mathrm{AD} / \mathrm{VAD}$, as detailed in Additional file 3.

The prevalence of dementia depending on age (55-59, $60-64,65-69,70-74,75-79,80-84,85-89,90-94$, and > 95 years; males and females were analysed separately for each age group) is shown in Additional file 4 . The prevalence of dementia and its subgroups (AD and VAD) increased progressively with increasing age in both males and females.

Other factors, such as sex (male and female), education level (illiterate, primary school, junior high school, senior high school and college), residence (city and rural), and occupation (worker, farmer, officer and housewife) were calculated and presented in Additional file 5. The prevalence of $\mathrm{AD}$ was significantly higher in females $(3.24,95 \%$ CI: $3.08-3.41 \%)$ than in males (1.58, 95\% CI: $1.46-1.70 \%)$, which was not observed for VAD. The prevalence decreased progressively with increasing education level for both $\mathrm{AD}$ and $\mathrm{VAD}$. The prevalence rates of $\mathrm{AD} / \mathrm{VAD}$ were significantly lower in the college group $(0.68,95 \% \mathrm{CI}$ : $0.31-1.48 \%) /(0.67,95 \% \mathrm{CI}: 0.34-1.32 \%)$ than in the illiterate group $(6.06,95 \%$ CI: $4.08-8.91 \%) /(2.42,95 \% \mathrm{CI}$ : $1.57-3.71 \%)$. The prevalence of dementia was not significantly different between the city and rural groups. The housewife group had a much higher prevalence of $\mathrm{AD}$ than the other occupations, but the result was biased by gender, because the term "housewife" inherently referred to females.

\section{Subgroup analysis}

The subgroup analysis based on region showed that the prevalence of $\mathrm{AD}$ decreased progressively from north China to south China. The prevalence rates in the northeast/north/northwest areas of north China were 3.62\%/ $3.08 \% / 2.63 \%$, respectively, which were higher than the prevalence rates in the central area (central/east China: $2.25 \% / 3.41 \%$, respectively). The south area (southwest/ south China: $2.24 \% / 2.25 \%$, respectively) had the lowest prevalence. The prevalence of VAD in the north region (northeast/north/northwest China: $2.24 \% / 1.62 \% / 1.51 \%$, respectively) was higher than the prevalence in the central and south regions (central/east/southwest/ south China: $0.64 \% / 0.99 \% / 0.45 \% / 1.02 \%$, respectively) (see Additional file 6).

We divided the studies into 6 groups according to the publication year (1985-1990, 1991-1995, 1996-2000, 2001-2005, 2006-2010 and 2010-2015) and found that the prevalence rates of $\mathrm{AD} / \mathrm{VAD}$ were $0.87 \% / 1.04$, $1.58 \% / 0.79, \quad 2.09 \% / 0.76, \quad 1.88 \% / 0.94,3.84 \% / 1.61$, and $3.77 \% / 1.49 \%$, respectively (see Additional file 7 ).

\section{Publication bias}

The $p$-value of Egger's test was 0.02972 . The asymmetric funnel plot showed that publication bias existed between the studies (Fig. 2).

\section{Meta-regression}

The outcomes of the univariate meta-regression analysis are presented in Additional file 8: Table S8 (online). Depending on the univariate meta-regression results, the prevalence rates of dementia/AD/VAD were higher in studies in which the publication year was after 2000 $(p=0.0002 / 0.0002 / 0.0062)$, and the sample size was greater than $3000(p<0.0001 / 0.0318 / 0.0025)$. The prevalence of dementia/AD/VAD was not significantly different according to the living area (neither city versus city plus rural areas nor city versus rural areas) or the diagnostic method (DSM-III/IV/IV-R vs. others). However, the prevalence of VAD was higher in studies from north China $(p<0.0001)$, which was not observed for dementia or AD. Then, we added two risk factors (geographical region and diagnostic criteria) to the multivariate analysis model (Table 2). When we set central China as the reference geographical region, only three groups (north China/northeast China/northwest China) showed higher prevalence rates of VAD $(p=0.0006 / 0.0009 / 0.0046)$, which was not observed in dementia or AD. When we set DSM-III/III-R as the reference diagnostic criteria, studies in which DSM-IV/IV-R were used had a higher prevalence of dementia/AD/VAD $(\mathrm{p}<0.0001 /<0.0001 /$ $0.0008)$ in the multivariate meta-regression analysis (see Additional file 8). 
Table 1 Characteristics of the included studies included in this article

\begin{tabular}{|c|c|c|c|c|c|c|c|c|c|c|}
\hline study & Location & $\begin{array}{l}\text { Urban/ } \\
\text { rural }\end{array}$ & Survey date & $\begin{array}{l}\text { Subject } \\
\text { no.(M/F) }\end{array}$ & $A D$ & VAD & Dementia & $\begin{array}{l}\text { Age } \\
\text { range }\end{array}$ & $\begin{array}{l}\text { Diagnostic } \\
\text { criteria }\end{array}$ & $\begin{array}{l}\text { Newcastle-Ottawa } \\
\text { scale }\end{array}$ \\
\hline Chen changhui1992 [9] & Beijing & C & $1986.1-1986.6$ & $5172(2385 / 2787)$ & 10 & 26 & 39 & $\geq 60$ & DSM-III & 8 \\
\hline gao surong1989 [10] & Beijing & C & 1986.4-1986.6 & $906(409 / 497)$ & 9 & 24 & 35 & $\geq 60$ & DSM-III & 8 \\
\hline gao zhixu 1993 [11] & Shanghai & $C+R$ & $\begin{array}{l}1990.10- \\
1990.12\end{array}$ & $3779(1499 / 2280)$ & 119 & 32 & 159 & $\geq 60$ & DSM-III-R & 9 \\
\hline wang dao1996 [12] & Shanghai & $C+R$ & 1991 & 1515(610/905) & 27 & 4 & 33 & $\geq 55$ & DSM-III-R & 8 \\
\hline mao ruihe1993 [13] & Fujian & $C+R$ & 1992.6-1992.9 & 1982(787/1195) & 29 & 22 & 58 & $\geq 60$ & DSM-III-R & 9 \\
\hline xue guanhua1997 [7] & Guangdong & $C+R$ & 1994 & $3285(1579 / 1706)$ & 23 & 18 & 47 & $\geq 60$ & DSM-III-R & 9 \\
\hline tang mouni1999 [14] & Sichuan & $\mathrm{R}$ & 1994 & $5987(2653 / 3334)$ & 86 & 11 & 104 & $\geq 65$ & DSM-III-R & 8 \\
\hline li zengjin1997 [15] & Beijing & C & 1994.11-1995.5 & 1027(372/655) & 38 & 25 & 63 & $\geq 60$ & DSM-III-R & 8 \\
\hline chen zhanying1998 [16] & Xinjiang & $C+R$ & $1995.1-1995.3$ & 2687(1380/1307) & 11 & 37 & 48 & $\geq 55$ & DSM-III & 8 \\
\hline Iv shuchen1998 [51] & Zhejiang & C & 1995.10-1996.6 & 1689(823/866) & 101 & 17 & 119 & $\geq 60$ & DSM-III-R & 8 \\
\hline zhang jingli1998 [25] & Beijing & C & $\begin{array}{l}1995.12- \\
1996.12\end{array}$ & $1243(760 / 483)$ & 17 & 12 & 29 & $\geq 60$ & DSM-III-R & 7 \\
\hline tang zhe2002 [52] & Beijing & $C+R$ & 1996-1998 & $2788(1356 / 1432)$ & 140 & 43 & 208 & $\geq 60$ & DSM-III-R & 9 \\
\hline $\begin{array}{l}\text { wang tianxiang1999 } \\
{[17]}\end{array}$ & Anhui & $C+R$ & 1997 & 2749(998/1751) & 109 & 27 & 143 & $\geq 65$ & ICD-10 & 9 \\
\hline zhou fen2001 [26] & Shanghai & $C+R$ & 1997 & $15,910(7148 / 8762)$ & 344 & 98 & 478 & $\geq 55$ & DSM-IV & 9 \\
\hline lishuran1999 [27] & Beijing & C & 1997 & 1593(697/896) & 22 & 15 & 40 & $\geq 60$ & ICD-10 & 7 \\
\hline tang mouni2001 [18] & Sichuan & $C+R$ & 1997.6-1998.4 & $5353(2552 / 2801)$ & 110 & 20 & 143 & $\geq 55$ & DSM-III-R & 9 \\
\hline xiao zhijie1999 [19] & Hunan & $C+R$ & 1997.6-1998.5 & $3287(1551 / 1736)$ & 47 & 26 & 86 & $\geq 55$ & DSM-IV & 9 \\
\hline qu qiumin2001 [28] & Shanxi & $C+R$ & 1997.9-1998.12 & $4850(2040 / 2810)$ & 100 & 54 & 172 & $\geq 55$ & DSM-IV & 9 \\
\hline zhang zhanxing [20] & Shanghai & $C+R$ & 1999 & 1186(597/589) & 11 & 5 & 33 & $\geq 55$ & DSM-III-R & 9 \\
\hline fan jianxiong2000 [48] & Jiangsu & C & 1999.5-1999.6 & $3268(1589 / 1679)$ & 31 & 16 & 48 & $\geq 60$ & DSM-III-R & 9 \\
\hline ma cui2005 [40] & Guangdong & $C+R$ & 2000 & $3780(1539 / 2241)$ & 128 & 44 & 182 & $\geq 65$ & DSM-IV & 9 \\
\hline tang mouni2005 [29] & Sichuan & $C+R$ & 2000.10-2001.3 & $3908(1924 / 1984)$ & 78 & 18 & 107 & $\geq 55$ & DSM-III-R & 9 \\
\hline gongjianbing2002 [53] & Hainan & $C+R$ & $\begin{array}{l}2001.10- \\
2001.12\end{array}$ & 2961(1210/1751) & 25 & 9 & 39 & $\geq 60$ & $\begin{array}{l}\text { CCMD-III- } \\
\mathrm{R}\end{array}$ & 9 \\
\hline zhou kaili2002 [21] & Chongqing & C & 2001.3-2001.5 & 1519(611/908) & 73 & 9 & 87 & $\geq 65$ & DSM-IV-R & 9 \\
\hline gao quwen2004 [54] & Guangdong & C & 2002 & 1839(1727/112) & 22 & 40 & 69 & $\geq 60$ & DSM-IV & 7 \\
\hline yuan yefeng2005 [30] & Jiangxi & $C+R$ & $2002.3-2002.4$ & 2126(1053/1073) & 72 & 14 & 93 & $\geq 60$ & ICD-10 & 8 \\
\hline chen weixiong2004 [31] & Hainan & C & $2002.5-2002.10$ & $12,628(6193 / 6435)$ & 80 & 113 & 193 & $\geq 60$ & DSM-III-R & 9 \\
\hline li wenbiao2003 [32] & Inner Mongolia & C & 2002.7-2002.8 & 2324(1846/478) & 31 & 31 & 62 & $\geq 60$ & ICD-10 & 7 \\
\hline li keqing2008 [33] & Hebei & $C+R$ & 2004 & 2126(1100/1026) & 166 & 52 & 218 & $\geq 65$ & DSM-IV & 9 \\
\hline $\begin{array}{l}\text { huang wenyong } 2007 \\
\text { [22] }\end{array}$ & Guizhou & C & 2005 & $3229(1227 / 2002)$ & 41 & 18 & 64 & $\geq 60$ & DSM-IV & 8 \\
\hline chen bin2009 [55] & Fujian & $\mathrm{C}$ & 2006.7-2007.4 & 2373(1039/1334) & 81 & 35 & 141 & $\geq 60$ & DSM-IV & 8 \\
\hline $\begin{array}{l}\text { wang hongyan2009 } \\
\text { [34] }\end{array}$ & Shandong & C & 2007 & $618(211 / 407)$ & 42 & 10 & 52 & $\geq 60$ & DSM-IV & 7 \\
\hline tan jiehua2007 [35] & Hubei & $C+R$ & 2007.1-2007.12 & $3908(1924 / 1984)$ & 78 & 18 & 107 & $\geq 55$ & DSM-III-R & 9 \\
\hline zheng xiuxia2010 [41] & Beijing & $C+R$ & 2007.5-2007.9 & 1756(737/1019) & 57 & 69 & 126 & $\geq 60$ & ICD-10 & 9 \\
\hline $\begin{array}{l}\text { Zhang honghui } 2008 \\
\text { [23] }\end{array}$ & Fujian & $\mathrm{R}$ & 2007.7-2007.11 & 2696(1104/1592) & 134 & 32 & 166 & $\geq 65$ & DSM-IV & 8 \\
\hline fan qinghua2011 [36] & Shanxi & $C+R$ & 2008 & 1826(1126/700) & 38 & 18 & 74 & $\geq 60$ & DSM-IV & 9 \\
\hline wang ying2010 [37] & Liaoning & C & 2008.1-2009.1 & 2100(1136/964) & 76 & 47 & 143 & $\geq 60$ & DSM-IV-R & 7 \\
\hline gao ying2009 [38] & Shanxi & C & 2008.3-2008.12 & $312(163 / 149)$ & 29 & 8 & 37 & $\geq 65$ & DSM-III-R & 7 \\
\hline ma yong 2013 [56] & Shanghai & C & 2010 & 2442(1130/1312) & 101 & 89 & 190 & $\geq 65$ & DSM-IV & 8 \\
\hline
\end{tabular}


Table 1 Characteristics of the included studies included in this article (Continued)

\begin{tabular}{|c|c|c|c|c|c|c|c|c|c|c|}
\hline study & Location & $\begin{array}{l}\text { Urban/ } \\
\text { rural }\end{array}$ & Survey date & $\begin{array}{l}\text { Subject } \\
\text { no.(M/F) }\end{array}$ & $A D$ & VAD & Dementia & $\begin{array}{l}\text { Age } \\
\text { range }\end{array}$ & $\begin{array}{l}\text { Diagnostic } \\
\text { criteria }\end{array}$ & $\begin{array}{l}\text { Newcastle-Ottawa } \\
\text { scale }\end{array}$ \\
\hline kang meiyu2011 [42] & Hebei & $C+R$ & $2010.1-2010.8$ & $3632(1937 / 1695)$ & 177 & 57 & 263 & $\geq 60$ & DSM-IV & 9 \\
\hline meng xinling2014 [39] & Xinjiang & $C+R$ & 2010.6-2012.8 & 2532(1221/1311) & 149 & 68 & 237 & $\geq 55$ & DSM-IV & 9 \\
\hline meng xinling2014 [39] & Xinjiang & $C+R$ & 2010.6-2012.8 & 1078(497/581) & 48 & 21 & 76 & $\geq 55$ & DSM-IV & 9 \\
\hline lao meili2011 [43] & Hainan & $C+R$ & 2010.7-2010.8 & $7665(3509 / 4156)$ & 111 & 48 & 159 & $\geq 55$ & HDS & 9 \\
\hline sun hongxian2012 [44] & Shanghai & C & 2010-2011 & $1472(666 / 806)$ & 56 & 18 & 79 & $\geq 60$ & DSM-IV-R & 9 \\
\hline cheng qi2013 [57] & Shanghai & $\mathrm{R}$ & 2011 & $1472(665 / 807)$ & 53 & 21 & 157 & $\geq 60$ & DSM-IV-R & 9 \\
\hline ji yong2015 [58] & Tianjin & $\mathrm{R}$ & $2011-2012$ & $5578(2482 / 3096)$ & 299 & 96 & 84 & $\geq 60$ & DSM-IV & 8 \\
\hline tang jiangping2014 [45] & Hunan & $C+R$ & $\begin{array}{l}2011.10- \\
2012.12\end{array}$ & $10,026(4845 / 5181)$ & 275 & 85 & 395 & $\geq 55$ & DSM-IV & 8 \\
\hline wei chongjuan2014 [46] & Tianjin & C & 2012 & 1324(1078/246) & 28 & 28 & 497 & $\geq 55$ & DSM-IV-R & 9 \\
\hline ding ding 2014 [47] & Shanghai & C & 2012 & $3141(1438 / 1703)$ & 113 & 25 & 72 & $\geq 60$ & DSM-IV-R & 7 \\
\hline li haihong2015 [59] & Guangxi & C & $2012.6-2014.3$ & $889(389 / 500)$ & 38 & 18 & 59 & $\geq 60$ & DSM-IV-R & 9 \\
\hline li chonghui2015 [60] & Tianjin & C & 2014 & 2532(1091/1441) & 144 & 59 & 228 & $\geq 60$ & DSM-IV-R & 9 \\
\hline
\end{tabular}

\section{Discussion}

In this systemic review and meta-analysis, we analysed 51 surveys conducted in mainland China from 1985 to 2015. The overall estimate of the dementia prevalence was $4.03 \%$ (95\% CI: $3.46-4.70 \%$ ), whereas the pooled prevalence of $\mathrm{AD} / \mathrm{VAD}$ was $2.44 \% / 1.09 \%$. The prevalence of dementia/AD/VAD was greater than that reported in a previous review [2] but lower than that reported in reviews that selected studies conducted after 2000 [3, 61, 62]; this finding was consistent with the results of a meta-regression that found that the prevalence rates of dementia/AD/VAD were significantly higher in studies published after 2000. The most common type was $\mathrm{AD}(64.6 \%)$, followed by VAD (26.8\%). The proportions of $\mathrm{AD} / \mathrm{VAD}$ were similar to the proportions reported in our previous study [2] but much higher than those observed in United States [63]. Furthermore, in some countries, such as Russia and Japan [64, 65], the prevalence of VAD was higher than that of $\mathrm{AD}$, which might be due to the inclusion of different diagnostic criteria, ethnicities and genetic factors [66, 67].

The prevalence of $\mathrm{AD}$ followed an obviously increasing pattern from the southern and central to the northern areas of China in the subgroup analysis. The prevalence of VAD was much higher in the northern area of China, but the difference between the central and southern areas of China was not significant. However, the economic discrepancies and differences in education between these areas were not significant, because all three areas included big cities (Beijing/Shanghai/ Guangzhou) and less developed provinces (e.g., Inner Mongolia /Anhui/Guangxi); this finding was consistent with a previous study [4]. Air pollution is much more severe in northern China, and recent studies have shown that PM 2.5 (PM2.5 refers to atmospheric particulate matter (PM) that have a diameter of less than $2.5 \mu \mathrm{m}$ which is an air pollutant that is a concern for people's health when levels in air are high) can injure brain

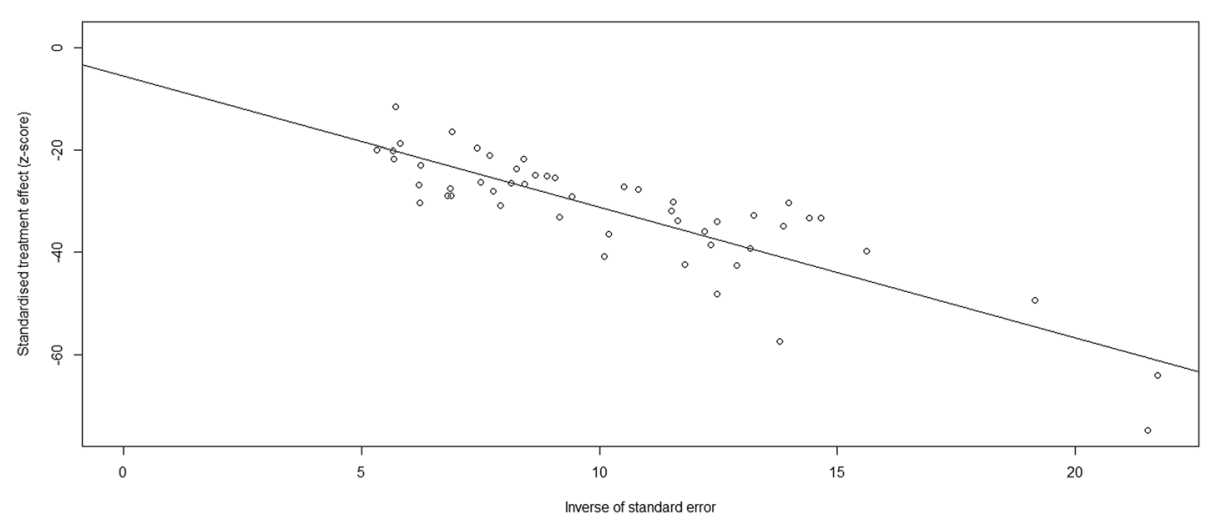

Fig. 2 The asymmetric funnel plot from Egger's test 
Table 2 Multivariate analysis (random effects model) of the meta-regression

\begin{tabular}{|c|c|c|c|}
\hline & Meta-regression Coefficient (\%) & $95 \% \mathrm{Cl}$ & $P$ \\
\hline \multicolumn{4}{|l|}{ Dementia } \\
\hline \multicolumn{4}{|l|}{ Geographical region } \\
\hline East China & 0.2965 & $-0.4241-1.0171$ & 0.4199 \\
\hline North China & 0.3952 & $-0.3414-1.1319$ & 0.2930 \\
\hline South China & 0.0179 & $-0.7462-0.7820$ & 0.9634 \\
\hline Central China (ref.) & - & - & - \\
\hline Northeast China & 0.7058 & $-0.3754-1.7871$ & 0.2007 \\
\hline Northwest China & 0.2726 & $-0.6063-1.1514$ & 0.5433 \\
\hline Southwest China & -0.1598 & $-0.9669-0.6472$ & 0.6979 \\
\hline \multicolumn{4}{|l|}{ Diagnostic criteria } \\
\hline DSM-III/III-R (ref.) & - & - & - \\
\hline DSM-IV/IV-R & 0.6930 & $0.3919-0.9940$ & $<0.0001$ \\
\hline ICD-10 & 0.3147 & $-0.2421-0.8715$ & 0.2680 \\
\hline HDS & -0.3239 & $-1.3516-0.7037$ & 0.5367 \\
\hline \multicolumn{4}{|l|}{$A D$} \\
\hline \multicolumn{4}{|l|}{ Geographical region } \\
\hline East China & 0.4463 & $-0.4022-1.2948$ & 0.3025 \\
\hline North China & 0.3469 & $-0.5217-1.2155$ & 0.4338 \\
\hline South China & 0.0150 & $-0.8853-0.9154$ & 0.9739 \\
\hline Central China (ref.) & - & - & - \\
\hline Northeast China & 0.5119 & $-0.7663-1.7900$ & 0.4325 \\
\hline Northwest China & 0.1775 & $-0.8587-1.2137$ & 0.7371 \\
\hline Southwest China & 0.0175 & $-0.9328-0.9679$ & 0.9711 \\
\hline \multicolumn{4}{|l|}{ Diagnostic criteria } \\
\hline DSM-III/III-R (ref.) & - & - & - \\
\hline DSM-IV/IV-R & 0.7478 & $0.4020-1.0935$ & $<0.0001$ \\
\hline ICD-10 & 0.2641 & $-0.3752-0.9034$ & 0.4181 \\
\hline HDS & -0.1414 & $-1.3096-1.0268$ & 0.8125 \\
\hline \multicolumn{4}{|l|}{ VAD } \\
\hline \multicolumn{4}{|l|}{ Geographical region } \\
\hline East China & 0.4028 & $-0.0984-0.9041$ & 0.1152 \\
\hline North China & 0.8777 & $0.3787-1.3767$ & 0.0006 \\
\hline South China & 0.4186 & $-0.1079-0.9450$ & 0.1192 \\
\hline Central China (ref.) & - & - & - \\
\hline Northeast China & 1.2313 & $0.5023-1.9603$ & 0.0009 \\
\hline Northwest China & 0.8385 & $0.2546-1.4225$ & 0.0049 \\
\hline Southwest China & 0.4186 & $-0.1079-0.9450$ & 0.1192 \\
\hline \multicolumn{4}{|l|}{ Diagnostic criteria } \\
\hline DSM-III/III-R (ref.) & - & - & - \\
\hline DSM-IV/IV-R & 0.6128 & $0.2542-0.9713$ & 0.0008 \\
\hline ICD-10 & 0.6050 & $-0.0534-1.2634$ & 0.0717 \\
\hline HDS & -0.2097 & $-1.4028-0.9835$ & 0.7305 \\
\hline
\end{tabular}


structures and cognition, which may ultimately increase the prevalence of AD/VAD. In 2016, an article published by Casanova et al. [68] found that long-term PM 2.5 exposure induced the loss of grey matter and white matter in older women, which could increase the prevalence of AD. Other studies confirmed that air pollution increased the prevalence of dementia [69-71], whereas some larger multi-centre studies published in Neurotoxicology and Lancet in 2017 also found that the prevalence of dementia was positively related to the level of air pollution [72, 73]. Therefore, we think climate environment factors and other socioeconomic factors may be potential influencing factors that require further research with well-designed studies to identify their impacts.

Chronologically, the prevalence rates of AD/VAD were higher after 2000 than before 2000. Wu et al. [4] showed an increasing trend in the prevalence from 1980 to 2014, but the significance disappeared when the authors accounted for changes in methodological factors (especially the diagnostic criteria). Renewal of the diagnostic criteria for dementia has been ongoing over the past few decades. Several new criteria have been proposed, including DSM-IV/IV-R, which replaced DSM-III/III$\mathrm{R}$, as well as other older criteria.

The important influence of methodological factors was confirmed by the meta-regression analysis in this study. According to the meta-regression outcomes, studies using the DSM-IV/IV-R had a higher prevalence of dementia/AD/VAD; we suspect that the increased diagnostic level (including the updated diagnostic criteria) partially caused the chronological increases in dementia/ $\mathrm{AD} / \mathrm{VAD}$.

We found that the prevalence rates of dementia/AD/ VAD were negatively correlated with education level [74]. A previous study by Langa et al. [75] reported a significant decline in the prevalence of dementia between 2000 and 2012. The negative relationship between the prevalence of $\mathrm{AD}$ and education level has been generally accepted and is consistent with the results of our study. Education was confirmed to be related to the prevalence of $\mathrm{AD}$ by former studies based on regional cerebral blood flow $[5,58]$ and genetic status [64]; thus, education may provide a reserve for the neuropath logical changes of $\mathrm{AD}$, delaying the progress of its clinical manifestations. However, the mechanism underlying the relationship between VAD and education remains unknown and requires further research.

The prevalence of $\mathrm{AD}$ was much higher in the female group than in the male group, as previously established. However, the prevalence of VAD did not show a significant difference between the two groups, indicating that gender was not a risk factor for VAD. In the analysis of stratified prevalence based on 5-year age groups, we found a positive relationship between dementia/AD/
VAD and age in both the male and female groups. Age was considered the pivotal influencing factor of dementia/AD/VAD. However, as we increased the number of elder groups to include those encompassing ages from 85 to 90 and $90+$ years, their total sizes were much smaller than those of the other groups, which might have led to a magnified result. Thus, more high-quality studies are needed to confirm this outcome.

Jia et al. [6] and Ji et al. [8] both reported that the prevalence rates of dementia/AD were higher in rural areas than in urban areas and that education was the most important influencing factor. However, the meta-regression results from this study found no significant difference between urban, rural and mixed areas, which was consistent with the result from $\mathrm{Wu}$ et al. [4]. The definition of urban or rural is not simple in China; simply stratifying by location is inaccurate and insufficient. Thus, more studies with stricter designs are needed in the future.

Our study has several limitations. Significant differences in the publication year, sample size and other factors were apparent, although the quality of the studies indicated their reliability. Depending on the results of the multivariate meta-regression analysis, we observed that the high heterogeneity between studies was caused by these risk factors. However, many risk factors were not considered. To obtain more reliable results, these risk factors and other potential factors should be better controlled. More information is needed from studies with identical designs in the future.

Because dementia is a serious societal problem, its prevention deserves more attention. According to the results of our study, some factors, such as air quality and education, are important for the prevention of dementia. However, more high-quality studies are required to resolve the many unknown factors related to dementia.

\section{Conclusions}

The prevalence of dementia/AD/VAD has increased over the past 30 years and may be affected by education level and diagnostic criteria. The prevalence of $\mathrm{AD} / \mathrm{VAD}$ was higher in northern than in southern China, which warrants further study.

\section{Additional files}

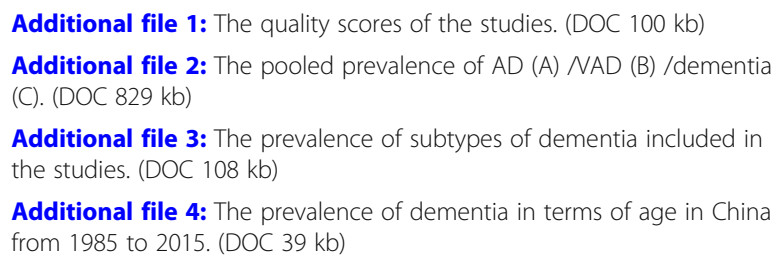

Additional file 3: The prevalence of subtypes of dementia included in the studies. (DOC $108 \mathrm{~kb}$ )

Additional file 4: The prevalence of dementia in terms of age in China from 1985 to 2015. (DOC $39 \mathrm{~kb}$ ) 
Additional file 5: Prevalence of dementia due to sex, education, occupation and residence difference. (DOC $36 \mathrm{~kb}$ )

Additional file 6: The subgroup analysis the prevalence of $A D(A)$ NAD (B) /dementia (C) based on region. (DOC $543 \mathrm{~kb}$ )

Additional file 7: The subgroup analysis the prevalence of $A D(A)$ NAD (B) /dementia (C) based on published year. (DOC 629 kb)

Additional file 8: Univariate meta-regression of the prevalence of dementia/ADNAD. (DOC $40 \mathrm{~kb}$ )

\section{Abbreviations}

AD: Alzheimer's disease; BDS: Blessed Dementia Scale; CCMD: Chinese Classification and Diagnostic Criteria of Mental Disorders; Cls: Confidence intervals; DSM-III: The Diagnostic and Statistical Manual of Mental Disorders, Third Edition; DSM-III-R: The Diagnostic and Statistical Manual of Mental Disorders, Third Edition; DSM-IV: The Diagnostic and Statistical Manual of Mental Disorders, Fourth Edition; DSM-IV-R: The Diagnostic and Statistical Manual of Mental Disorders, Fourth Edition, revised; HDS: Hasegawa Dementia Scale; ICD-10: International Classification of diseases-10; MMSE: Mini-Mental State Examination; NINCDS-ADRDA: National Institutes of Neurological Disorders and Stroke-Alzheimer's Disease and Related Disorders Association; NINDS-AIREN: National Institute of Neurological Disorders and Stroke and Association Internationale pour la Recherche et 1'Enseignement en Neurosciences; NOS: Newcastle-Ottawa scale; PRISMA: Systematic Reviews and Meta-Analyses; VAD: Vascular dementia

\section{Acknowledgements}

We thank AJE for English language editing.

\section{Funding}

Zhejiang Provincial Natural Science Foundation of China LY15H180007), the Medical and Health Science and Technology Project of Zhejiang Province (2015KYB153) and the National Natural Science Foundation of China (No. 81471704) supported in data retrieval and statistics.

\section{Availability of data and materials}

All data generated or analysed during this study are included in this published article (and its supplementary information files).

\section{Authors' contributions}

MD conceived the idea. YZ screened and enrolled the articles and wrote the main manuscript. $\mathrm{XL}$ checked and revised the text. BZ and $\mathrm{HL}$ extracted and analysed the data. WW reconciled disagreements. JY and JZ provided statistical support. All authors reviewed the manuscript. All authors read and approved the final manuscript.

\section{Ethics approval and consent to participate}

Not applicable.

\section{Consent for publication}

Not applicable.

\section{Competing interests}

The authors declare that they have no competing interests.

\section{Publisher's Note}

Springer Nature remains neutral with regard to jurisdictional claims in published maps and institutional affiliations.

\section{Author details}

'Department of Ultrasound, the First Affiliated Hospital, College of Medicine, Zhejiang University, Hangzhou 310003, People's Republic of China. ${ }^{2}$ The Department of Nuclear Medicine, the First Affiliated Hospital, College of Medicine, Zhejiang University, 79 QingChun Road, Hangzhou 310003 People's Republic of China. ${ }^{3}$ Key Laboratory of Precision Diagnosis and Treatment for Hepatobiliary and Pancreatic Tumours of Zhejiang Province, Hangzhou 310003, People's Republic of China.
Received: 30 May 2018 Accepted: 16 April 2019

Published online: 15 May 2019

\section{References}

1. Fiest KM, Jetté N, Roberts Jl, Maxwell CJ, Smith EE, Black SE, et al. The prevalence and incidence of dementia: a systematic review and meta-analysis. Can J Neurol Sci. 2016:43:3-50.

2. Dong $M$, Peng $B$, Lin $X$, Zhao J, Zhou $Y$, Wang $R$. The prevalence of dementia in the People's Republic of China: a systematic analysis of 1980-2004 studies. Age Ageing. 2007;36:619-24.

3. Liu B, Wang J, Xiao Y. Prevalence of senile dementia in people $\geq 60$ years in China: a meta-analysis. Chin J Epidemiol. 2016;37:11.

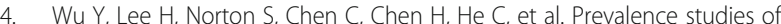
dementia in mainland China, Hong Kong and taiwan: a systematic review and meta-analysis. PLoS One. 2013;8:e66252.

5. Stern Y, Stricks L, Alexander G. Relationship between occupational demands and parietotemporal perfusion in Alzheimer's disease. Ann Neurol. 1992;32:270

6. Jia J, Wang F, Wei C, Zhou A, Jia X. The prevalence of dementia in urban and rural areas of China. Alzheimers Dement. 2014;10:1-9.

7. Xue GH, Shao YC, Zhu GZ. An epidemiological study on dementia in Guangdong province. J Pract Med (Chin). 1997:13:371-2.

8. Ji Y, Shi Z, Zhang Y, Liu S, Liu S, Yue W, et al. Prevalence of dementia and Main subtypes in rural northern China. Dement Geriatr Cogn. 2015;39:294-302

9. Chen $\mathrm{CH}$, Shen YC, Li S. An epidemiological survey of dementia in Xicheng district, Beijing. Chin J Mental Health. 1992;6:49-52.

10. Gao SR, Zhang LP. A survey of dementia in 906 elderly. Chin J Geriatr. 1989:8:75-8.

11. Gao ZX, Liu FG, Fang YS. A study of morbidity rate of senile dementia among aged in urban and rural areas. Chin J Neurol Psychiatry. 1993;26: 209-12.

12. Wang D, Bu SM. A survey of prevalence of dementia in Shanghai. Shanghai Arch Psychiatry. 1995;7:76-8.

13. Mao RH, Zhang RR, Ni YX. Prevalence of senile dementia in urban and rural areas of Longyan. Chin J Gerontol. 1993;13:226-8.

14. Tang MN, Guo YB, Xiang MZ. Epidemiology of senile dementia and Alzheimer's disease in the rural area. J Clin Psychol Med. 1999;9:20-2.

15. Li ZJ, Dong ZX, Lv SX. The situation of prevalence of dementia in Dongcheng District, Beijing. Chin J Epidemiol. 1997;16:372.

16. Chen ZY, Zhang L, Lai YX. The epidemiology of vascular dementia and Alzheimer's dementia in Shihezi, Xinjiang, China. Chin J Neuroimmunol Neurol. 1998;5:44-8

17. Wang TX, Sui JZ, Wei XB. The prevalence of senile dementia in urban and rural areas of Anhui province. Occup Health. 1999;15:43-5.

18. Tang MN, Liu XH, Zou XY. The prevalence of senile dementia in the urban and the rural areas in Chengdu. Chin J Psychiatry. 2001;34:226-30.

19. Xiao ZJ, Li QX, Liao EY. An epidemiological study on dementia in Furong district, Changsha. Chin J Clin psychol. 1999;7:221-3.

20. Zhang ZX. An epidemiological distribution on dementia in Baoshan district, Shanghai. J Health Psychol. 2000;8:536-8.

21. Zou KL, Qi J, He Y. A cross-sectional study of senile dementia in Liang Lukou street of Yuzhong county of Chongqing. Chin J Geriatr. 2002;21:433-5

22. Huang $W Y$, Yang $X$, Yang JY Investigation on prevalence of dementia among elderly in urban communities of Guiyang city. Chin J Public Health. 2007;23:983-5

23. Li $\mathrm{H}$, Zhang $\mathrm{HH}$, Huang $\mathrm{H}$. Prevalence of dementia among rural elderly in Gushan township, Fuzhou. Chin J Epidemiol. 2009:30:772-5.

24. Matthews, et al. A two-decade comparison of prevalence of dementia in individuals aged 65 years and older from three geographical areas of England: results of the Cognitive Function and Ageing Study I and II. Lancet. 2013:382:1405-12.

25. Zhang JL, Zhang HH, Tao GS. An epidemiological study on senile dementia among 1390 elderly people in Haidian District, Beijing. Chin J Epidemiol. 1998;19:18-20

26. Zhou F, Hong Z, Huang MS. Prevalence of dementia in Shanghai urban and rural area. Chin J Epidemiol. 2001:22:386-90.

27. Li SR, Chen CH, Zhang WZ. The prevalence of dementia and depression of elderly in the urban community in Beijng. Chin J Ment Health. 1999;13:266-8. 
28. Qu QM, Qiao J, Yang JB. Study of the senile dementia among elderly people in Xi'an, China. Chin J Geriatr. 2001;20:283-6.

29. Tang MN, Liu XH, Lu J. Comparison of prevalence of dementia between in 1997 and 2000 surveys in the urban and rural community in Chengdu. Chin J Psychiatry. 2005;3:170-3.

30. Yuan YF, Wan AL, Chen JY. Epidemiological report of senile dementia in Nanchang city. Chin J Neuromed. 2004;4:65-7.

31. Chen WX, Wu CD, Huang JD. Epidemiological survey of Alzheimer's disease and cerebrovascular dementia in Hainan. Chin Trop Med. 2004;4:1056-7.

32. Li WB, Wang Y, Wei LQ. A survey of prevalence of senile dementia in retired elderly people. Lit Inf Prev Med. 2003;9:643-4.

33. Li KQ, Jiang $Q P$, Cui $\sqcup$. Epidemiological investigation of Alzheimer disease in the urban and rural areas in Hebei Province. Chin J Psychol. 2008;1:12513.

34. Wang HY, Zhang YQ, Chen XR. Epidemiological survey of senile dementia among elderly people in communities of Tai'an. Chin J Public Health. 2009; 25:899-900.

35. Tan $\mathrm{JH}$. Investigation on prevalence of senile dementia in Hubei ethnic minority areas. Med Forum. 2007;11:703-5.

36. Fan $\mathrm{QH}$, Zheng JZ. Investigation of prevalence of Alzheimer and its risk factors. Mod Prev Med. 2011;38:3029-33.

37. Wang Y, Jiang LC, Gao Y. Epidemiological survey of senile dementia in the military retired cadres of Dalian. Chin J Convalescent Med. 2010;19:567-9.

38. Gao Y, Li L, Liu JL. Taiyuan City 435 elderly Alzheimer's disease status of the investigation. Chin Mod Med. 2009;16:126-7.

39. Meng XL, Liu T, Liu YX. Survey of the incidence of elderly dementia of Kazak ethnic group in Xinjiang Uygur autonomous region. Chin J Neurol. 2014;47: 491-4.

40. Ma C, Tang MN, Guo YB. The prevalence of dementia in the urban and rural aged in Guangzhou. Chin J Psychiatry. 2005;4:39-42.

41. Zheng XX. An epidemiologic survey of Alzheimer's disease in Mentougou District of Beijing. J Neurosci Ment Health. 2010;10:196-8.

42. Kang MY, Gao YM, Huo HQ. Epidemiological features of chronic and Aizheimer'S diseases in the community-based elderly living in cities and counties in Hebei province. Chin J Epidemiol. 2011;32:672-5.

43. Lao ML, Zhang HY, Yi XN. Epidemiological survey of Alzheimer 's disease in Hainan. Chin J Geriatr. 2011;31:4016-8.

44. Sun HX, Wu YW, Ye FL. Prevalence of dementia among elderly people in Sheshan town, Songjiang district, Shanghai. J Intern Med Concepts Pract. 2012;7:91-5.

45. Tang JP, Zou W, Jiang HY. Epidemiological survey and analysis about senile dementia among persons $\geq 55$ years old living in Changsha area. J Neurosci Ment Health. 2014;14:164-6.

46. Wei CJ, Cheng Y, Zhang Y. Risk factors for dementia in highly educated elderly people in Tianjin, China. Clin Neurol Neurosur. 2014;122:4-8.

47. Ding D, Zhao QH, Guo QH. The Shanghai aging study: study design, baseline characteristics, and prevalence of dementia. Neuroepidemiology. 2014:43:114-22.

48. Fan JX, Yan $J \mathrm{~L}$, Chen $\mathrm{ZH}$. An epidemiological report of senile dementia in Nanjing area. J Clin psychol Med. 2000;10:137-8.

49. Freeman MF, Tukey JW. Transformations related to the angular and the square root. Ann Math Stat. 1950;21:607-11.

50. Wilson EB. Probable inference, the law of succession, and statistical inference. J Am Stat Assoc. 1927;22:209-12.

51. Lü SC, Yu HM, Chen YH. Epidemiological survey of senile dementia in Dinghai District, Zhoushan City residemts. Chin J Psychiatry. 1998;4:33-5.

52. Tang Z, Meng C, Dong HQ. An epidemiological study in urban and rural areas in Beijing. Chin J Gerontol. 2002;22:224-46.

53. Gong JB, He ZY, Li DF. An epidemiological survey of senile dementia in Zhanzhou, Hainan. Hainan Med. 2002;6:52-3.

54. Gao QW, Huang CY, Liu J. Investigation on the prevalence of dementia in retired cadres in military. Guangzhou Med. 2004;25:203-4.

55. Chen B, Luo WW, Chen LL. Condition of senile dementia and analysis of its dangerous social-psychological factors. Fujian Med J. 2009;31:133-6.

56. Ma $Y$, Jiang ZP, Wang JW. The prevalence of major subtypes of dementia in people over 65 years old in Xujiahui street, Shanghai. Chin J Geriatr. 2013; 33:1365-6.

57. Cheng Q, Sun HX, Ye FL. Dementia among elderly in Shanghai suburb: a rural community survey. J Alzheimers Dis. 2014;39:883-9.
58. Stern Y, Alexander GE, Prohovnik I. Inverse relationship between education and parietotemporal perfusion deficit in Alzheimer's disease. Ann Neurol. 1992;32:371-5

59. $\mathrm{Li} \mathrm{HH}, \mathrm{Hu} \mathrm{CY}$, Wei DM. Prevalence of dementia among elderly people in Santang community, Nanning city. Chin J Geriatr Care. 2015;13:29-30.

60. Li CH, Yang LS, Zhao L. Epidemiological investigation on the prevalence of senile dementia among the patients served by a community hospital in Beichen District, Tianjin City. Pract Prev Med. 2015;22:305-7.

61. Lei T, Ma YN, Nie HW. Meta-analysis of evaluation of current prevalence of dementia in elderly in China. Mod Prev Med. 2012;39:809-11.

62. Dong YH, Mao XQ, Liu L. Prevalence of dementia among Chinese people aged 60 years and over: a meta-analysis. Chin J Public Health. 2014;30:50215.

63. Mehta KM, Yeo GW. Systematic review of dementia prevalence and incidence in US race/ethnic populations. Alzheimers Dement. 2017:13:72-83.

64. Ikeda M, Hokoishi K, Maki N. Increased prevalence of vascular dementia in Japan: a community-based epidemiological study. Neurology. 2001;57:839-

65. Karasawa A, Homma A. Recent changes in the prevalence of dementia in the Tokyo metropolis. In: Hasegawa K, Homma A, editors. Psychogeriatrics: Biomedical and Social Advances, vol. 1. Amsterdam: Excerpta Medica; 1990. p. 24-9.

66. Katzman R, Zhang MY, Chen PJ. Effects of apolipoprotein E on dementia and aging in the Shanghai survey of dementia. Neurology. 1997:49:779-85.

67. Evans DA, Beckett LA, Field TS. Apolipoprotein E [small element of] 4 and incidence of Alzheimer disease in a community population of older persons. JAMA. 1997;277:822-4

68. Casanova R, Wang X, Reyes J, Akita Y, Serre ML, Vizuete W, et al. A voxelbased morphometry study reveals local brain structural alterations associated with ambient fine particles in older women. Front Hum Neurosci. 2016:10:495-503.

69. Chen J, Wang X, Wellenius GA, Serre ML, Driscoll I, Casanova R, et al. Ambient air pollution and neurotoxicity on brain structure: evidence from women's health initiative memory study. Ann Neurol. 2015;78:466-76.

70. Block ML, Elder A, Auten RL, Bilbo SD, Chen H. The outdoor air pollution and brain health workshop. Neurotoxicology. 2012;33:972-84.

71. Gatto NM, Henderson WW, Hodis HN, St. John JA, Lurmann F, Chen J, et al. Components of air pollution and cognitive function in middle-aged and older adults in Los Angeles. Neurotoxicology. 2014:40:1-7.

72. Melinda CP, Sara DA, Jeff DY, Jennifer W. Exposure to air pollution as a potential contributor to cognitive function, cognitive decline, brain imaging, and dementia: a systematic review of epidemiologic researchOriginal research article. Neurotoxicology. 2016;56:235-53.

73. Hong C, Jeffrey CK, Ray C, Karen T, Paul JV, Aaron VD, et al. Living near major roads and the incidence of dementia, Parkinson's disease, and multiple sclerosis: a population-based cohort study. Lancet. 2017:389:71826.

74. Li S, Yan F, Li G. Is the dementia rate increasing in Beijing? Prevalence and incidence of dementia 10 years later in an urban elderly population. Acta Psychiatr Scand. 2007:115:73-9.

75. Langa KM, Larson EB, Crimmins EM, Faul JD, Levine DA. A comparison of the prevalence of dementia in the United States in 2000 and 2012. JAMA Intern Med. 2017;177:51-8.

Ready to submit your research? Choose BMC and benefit from

- fast, convenient online submission

- thorough peer review by experienced researchers in your field

- rapid publication on acceptance

- support for research data, including large and complex data types

- gold Open Access which fosters wider collaboration and increased citations

- maximum visibility for your research: over $100 \mathrm{M}$ website views per year

At $\mathrm{BMC}$, research is always in progress.

Learn more biomedcentral.com/submission 